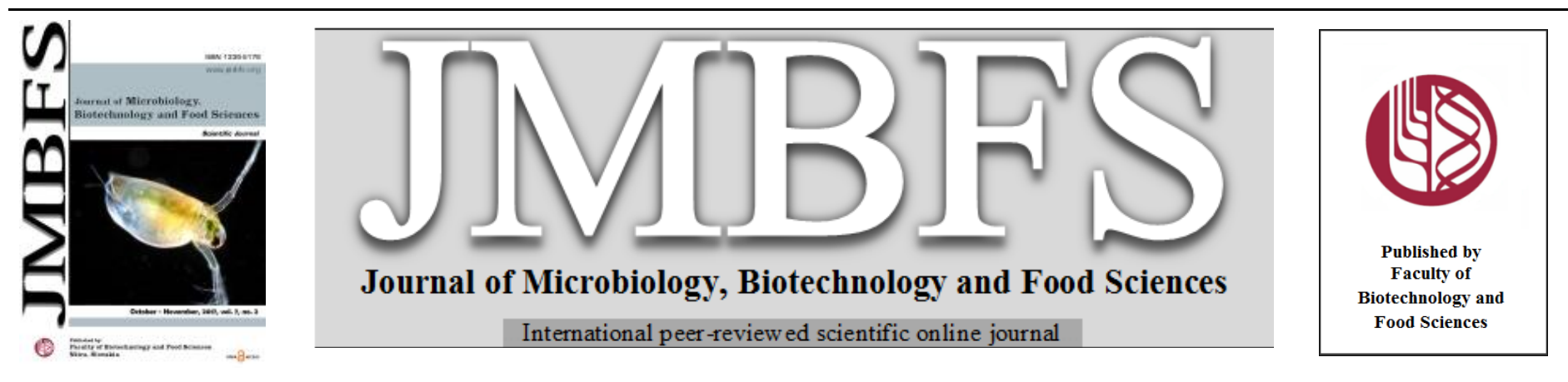

\title{
VARIATION IN THE OCCURENCE OF AFLATOXINS IN VARIOUS PROCESSED FORMS OF DRIED GINGER
}

\section{Dinesh Singh Bisht ${ }^{*}$ and K.R.K. Menon ${ }^{2}$}

\author{
Address(es): Dinesh Singh Bisht \\ ${ }^{1}$ Spices Board, Quality Evaluation Laboratory, Mumbai, India-400710. \\ ${ }^{2}$ Spices Board, Quality Evaluation Laboratory, Kochi, India-682025.
}

*Corresponding author: dsbisht28feb@gmail.com

doi: 10.15414/jmbfs.2017.7.2.110-112

\section{ARTICLE INFO}

Received 23. 5. 2017

Revised 27. 6. 2017

Accepted 9. 7. 2017

Published 1. 10. 2017

Short communication

OPEN $\partial_{\text {ACCESS }}$

\section{ABSTRACT}

A total 30 samples of three forms of dried ginger viz whole, sliced and ground (10 samples each), were collected from different local markets of Delhi, India and analyzed for the occurrence of aflatoxins with HPLC equipped with fluorescence detector. Aflatoxins in dried whole ginger were not detected, in dried sliced ginger the range of total aflatoxin was $3.64 \mu \mathrm{g} / \mathrm{kg}-7.52 \mu \mathrm{g} / \mathrm{kg}$ and in dried ground ginger the range of total aflatoxin was $2.99 \mu \mathrm{g} / \mathrm{kg}-5.25 \mu \mathrm{g} / \mathrm{kg}$. The susceptibility of the various forms of the dried ginger towards aflatoxins contamination was in the order whole<ground<sliced. The occurrence of aflatoxins B1 and G1 were more pronounced as compared to aflatoxins B2 and G2.

Keywords: Aflatoxin, Ginger, HPLC, Spices

\section{INTRODUCTION}

Ginger (Zingiber officinale) belongs to the family Zingiberaceae and has been widely used as spice and flavoring agent in foods for over 2000 years (Bartley $\&$ Jacobs, 2000). Ginger has beneficial uses in both traditional and modern medicine for the treatment of nausea, vomiting, motion sickness, diarrhea, and digestive and respiratory disorders. Furthermore, ginger also possesses numerous significant pharmacological properties such as anti-inflammatory, antimicrobial, anticarcinogenic, analgesic and antioxidant activities ( Ali et al., 2008; Butt \& $\underline{\text { Sultan, 2011). Gingerols and its dehydrated derivatives, shogaols, and degraded }}$ derivative, zingerone, are considered the major active components responsible for antiemetic, antipyretic, anti-cancer and anti-inflammatory activities of ginger (Grzanna et al., 2005; Shukla \& Singh, 2007). Dried ginger is normally traded in either the whole or sliced forms. When reduced to the ground form, it is used as an ingredient in various spice blends and in the food processing industry.

Aflatoxins (AFs) are secondary metabolites which are of great concern because of their detrimental effects on human and animal health, including carcinogenic, mutagenic, teratogenic, and immunosuppressive effects (Eaton \& Gallagher, 1994), aflatoxins $B_{1}, B_{2}, G_{1}$ and $G_{2}$ are normally found in foods (Wogan et al., 2012).

They are produced mainly by three species of Aspergillus: Aspergillus flavus, Aspergillus parasiticus and Aspergillus nomius, and can occur in a wide range of important raw food commodities including spices, cereals, nuts, figs and dried fruits. These fungi are capable of growing when temperature, relative humidity and product moisture are favorable (Iamanaka $\boldsymbol{e t}$ al., 2007). Spices, such as chillies, turmeric, black pepper, coriander and dry ginger, may become contaminated with aflatoxins, during pre-harvest, post-harvest, storage and transport. Ginger is prone to be contaminated by mycotoxins during pre- and post-harvest, and although a few publications have reported that AFs and OTA have been found in ginger and its related products with various contamination levels (Whitaker et al., 2009; Wen et al., 2014), the present study is to determine the occurrence aflatoxins in dried whole, sliced and ground ginger.

\section{MATERIAL AND METHODS}

\section{Chemicals and Reagents}

Aflatoxins standard (Supelco, Aflatoxin mix, USA) was purchased from Supelco, aflatoxin immunity affinity columns (Aflatest-P columns) were purchased from VICAM (USA), HPLC grade methanol, was purchased from Merck (USA) and milli-Q water (Millipore Corporation, USA) was used during the experiment. Working solutions were prepared immediately before analysis.
Samples

30 samples of various forms of dried ginger viz whole, sliced and ground were collected from different local markets (Delhi, India). Prior to analysis the samples were packed in plastic bags and stored at $4{ }^{\circ} \mathrm{C}$, all the samples were extracted and analyzed in duplicate.

\section{Sample preparation}

Samples were prepared by following ASTA (American Spice Trade Association) analytical method 24.2.

\section{Extraction}

Samples were ground in a blender and homogenized. $25 \mathrm{~g}$ of sample and $5 \mathrm{~g}$ of $\mathrm{NaCl}$ was weighed and transferred to a blender jar (Warring, VIACAM, USA),

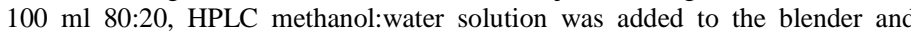
blended for 1 minute, than filtered into a $250 \mathrm{ml}$ beaker using fluted filter paper. $10 \mathrm{ml}$ of the filtrate was diluted to $50 \mathrm{ml}$ with Milli-Q water and again filtered through microfiber filter paper. $10 \mathrm{ml}$ of this filtrate was taken for immunoaffinity column cleanup.

\section{Immunoaffinity column cleanup}

The aflatest columns were placed on a pump stand and $10 \mathrm{ml}$ of the above filtrate was passed through the column, the column was rinsed with Milli-Q water 2-3 times and $1 \mathrm{ml}$ of HPLC methanol was eluted through the aflatest column using micropipette and collected in a vial for further analysis.

\section{HPLC condition}

HPLC analysis was performed on Water's Allaince HPLC system fitted with photochemical reactor for enhanced detection (PHRED) for post column photochemical derivatization of aflatoxins and fluorescence detector. The chromatographic column used was Sunfire ${ }^{\mathrm{TM}}$ Column $(\mathrm{C} 18,5.0 \mu \mathrm{m}, 4.6 \mathrm{~mm} \times$ $100 \mathrm{~mm}$, Water's, USA). The mobile phase was methanol:water $(45: 55, \mathrm{v} / \mathrm{v})$ Excitation and emission wavelengths were set at 365 and $464 \mathrm{~nm}$, respectively in the fluorescence detector. The flow rate was $1 \mathrm{ml} / \mathrm{min}$ and the column temperature was maintained at $40^{\circ} \mathrm{C}$. The injection volume was $50 \mu 1$. 


\section{Method validation}

The Limit of detection (LOD) and Limit of quantification (LOQ) were determined by injecting the blank ginger samples spiked with a certain concentration of mixed standard solutions and were calculated as signal-to-noise $(\mathrm{S} / \mathrm{N})$ ratio of 3:1 and 10:1 respectively. $\mathrm{LOD}$ and $\mathrm{LOQ}$ for $\mathrm{AFB}_{1}$ and $\mathrm{AFG}_{1}$ were $0.2 \mu \mathrm{g} / \mathrm{kg}$ and $0.5 \mu \mathrm{g} / \mathrm{kg}$, respectively, and for $\mathrm{AFB}_{2}$ and $\mathrm{AFG}_{2}$ were 0.15 and 0.5 $\mu \mathrm{g} / \mathrm{kg}$, respectively. The detailed results of LOD and LOQ were reported in Table 1.

Table 1 Linearity, LODs and LOQs

\begin{tabular}{lccc}
\hline Analytes & Linearity R & $\begin{array}{c}\text { LOD } \\
(\mu \mathrm{g} / \mathrm{kg})\end{array}$ & $\begin{array}{c}\text { LOQ } \\
(\mu \mathrm{g} / \mathrm{kg})\end{array}$ \\
\hline $\mathrm{AFB}_{1}$ & 0.9986 & 0.2 & $0.5 \mu \mathrm{g} / \mathrm{kg}$ \\
$\mathrm{AFB}_{2}$ & 0.9981 & 0.15 & $0.5 \mu \mathrm{g} / \mathrm{kg}$ \\
$\mathrm{AFG}_{1}$ & 0.9985 & 0.2 & $0.5 \mu \mathrm{g} / \mathrm{kg}$ \\
$\mathrm{AFG}_{2}$ & 0.9984 & 0.15 & $0.5 \mu \mathrm{g} / \mathrm{kg}$ \\
\hline
\end{tabular}

Calibration curves for $\mathrm{AFB}_{1}$ and $\mathrm{AFG}_{1}$ were prepared between six points of 0.5 to $20 \mu \mathrm{g} / \mathrm{kg}$ with linear response, $\mathrm{R}^{2}=0.9986$ and 0.9985 respectively. The calibration curves for $\mathrm{AFB}_{2}$ and $\mathrm{AFG}_{2}$ were prepared between 0.15 and $6 \mu \mathrm{g} / \mathrm{kg}$ with linear response, $\mathrm{R}^{2}=0.9981$ and 0.9984 respectively. The recovery experiments were performed at three spiking levels $(0.5,2.0$ and $5.0 \mu \mathrm{g} / \mathrm{kg}$ for $\mathrm{AFB}_{1}, \& \mathrm{AFG}_{1} ; 0.15,0.6$ and $1.5 \mu \mathrm{g} / \mathrm{kg}$ for $\mathrm{AFB}_{2}$ and $\mathrm{AFG}_{2}$ ) by adding an appropriate amount of aflatoxins standard solutions to the blank ginger samples The spiked samples were extracted, cleaned-up, derivatized and analyzed by HPLC-FLD as previously described.

The recovery values of the method for the four analytes were displayed in Table

Table 2 Recovery

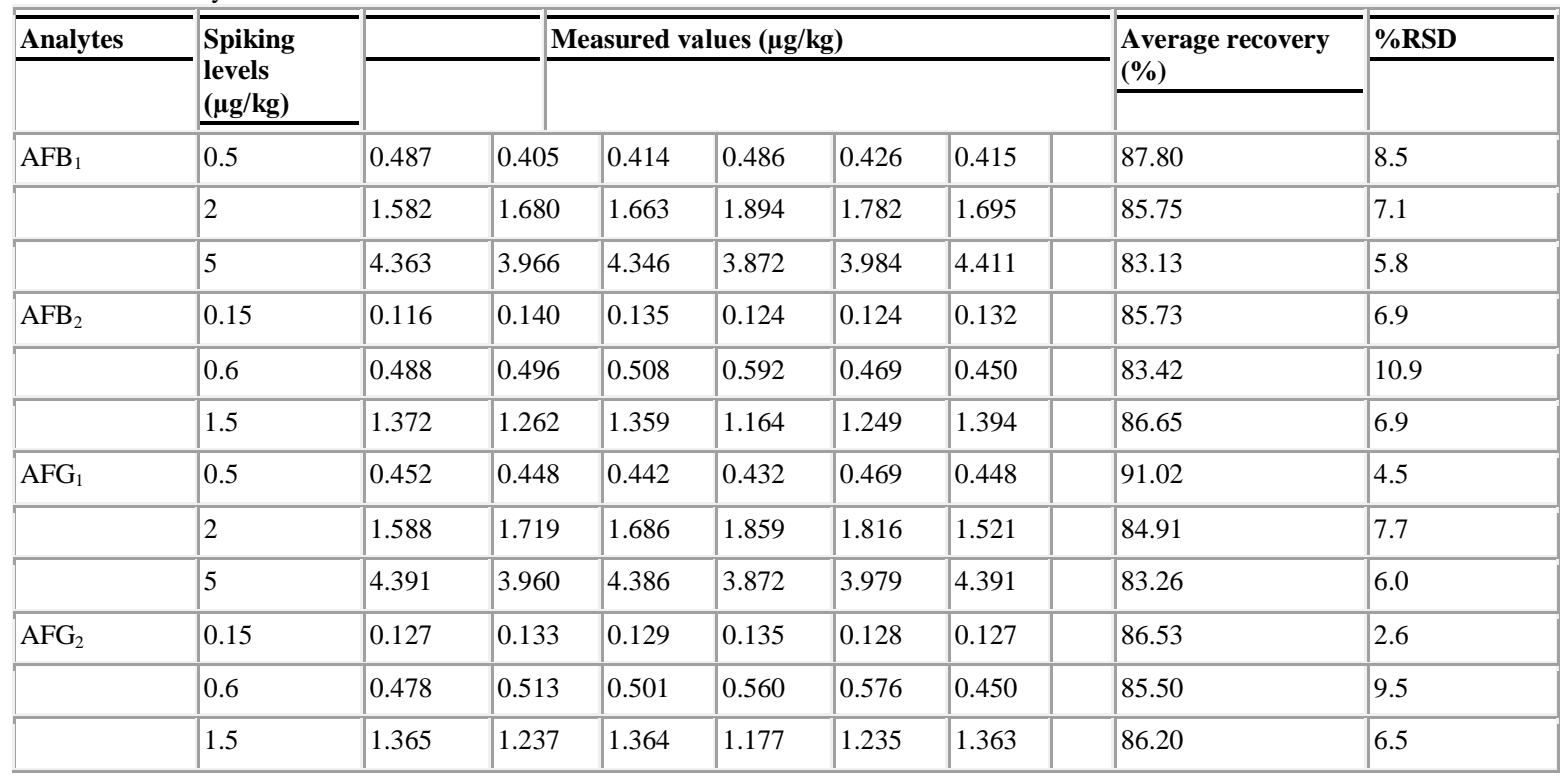

The average recoveries ranged from 83.13 to $91.02 \%$ for aflatoxins with \%RSDs of ranged from 2.6-10.9.

\section{RESULTS AND DISCUSSION}

A total of 30 samples were analyzed for the occurrence of aflatoxins, 10 samples each of dried whole, sliced and powdered ginger shown in Table 3 and 4.

Table 3 Occurrence levels of four investigated aflatoxins in tested samples

\begin{tabular}{|l|l|l|l|l|l|}
\hline \multirow{2}{*}{ Sample type } & Samples & \multicolumn{4}{l|}{ Range of aflatoxins in $\mu \mathrm{g} / \mathrm{kg}$} \\
\cline { 3 - 6 } & & $\mathrm{AFB}_{1}$ & $\mathrm{AFB}_{2}$ & $\mathrm{AFG}_{1}$ & $\mathrm{AFG}_{2}$ \\
\hline Dried ginger whole & 10 & $\mathrm{ND}$ & $\mathrm{ND}$ & $\mathrm{ND}$ & $\mathrm{ND}$ \\
\hline Dried ginger sliced & 10 & $1.08-3.31$ & $\mathrm{ND}$ & $\begin{array}{l}2.18- \\
4.86\end{array}$ & $\mathrm{ND}$ \\
\hline Dried ginger powder & 10 & $1.13-2.45$ & $0.15-$ & $1.86-$ & $0.15-$ \\
& & & 0.23 & 2.87 & 0.19 \\
\hline Total & 30 & & & & \\
\hline
\end{tabular}

Table 4 Contamination levels of four investigated aflatoxins in the tested samples

\begin{tabular}{lccccc} 
Samples & \multicolumn{1}{c}{ No. } & \multicolumn{4}{c}{ Amount $(\boldsymbol{\mu g} / \mathbf{k g})$} \\
& & $\mathrm{AFB}_{1}$ & $\mathrm{AFB}_{2}$ & $\mathrm{AFG}_{1}$ & $\mathrm{AFG}_{2}$ \\
\hline $\begin{array}{l}\text { Dried ginger } \\
\text { whole }\end{array}$ & 1 & $\mathrm{ND}$ & $\mathrm{ND}$ & $\mathrm{ND}$ & $\mathrm{ND}$ \\
& 2 & $\mathrm{ND}$ & $\mathrm{ND}$ & $\mathrm{ND}$ & $\mathrm{ND}$ \\
& 3 & $\mathrm{ND}$ & $\mathrm{ND}$ & $\mathrm{ND}$ & $\mathrm{ND}$ \\
& 4 & $\mathrm{ND}$ & $\mathrm{ND}$ & $\mathrm{ND}$ & $\mathrm{ND}$ \\
& 5 & $\mathrm{ND}$ & $\mathrm{ND}$ & $\mathrm{ND}$ & $\mathrm{ND}$ \\
& 6 & $\mathrm{ND}$ & $\mathrm{ND}$ & $\mathrm{ND}$ & $\mathrm{ND}$ \\
\hline
\end{tabular}

\begin{tabular}{|c|c|c|c|c|c|}
\hline & 7 & ND & ND & ND & ND \\
\hline & 8 & ND & ND & ND & ND \\
\hline & 9 & ND & ND & ND & ND \\
\hline & 10 & ND & ND & ND & ND \\
\hline \multirow[t]{10}{*}{$\begin{array}{l}\text { Dried ginger } \\
\text { sliced }\end{array}$} & 1 & 1.47 & ND & 2.18 & ND \\
\hline & 2 & 3.13 & ND & 3.76 & ND \\
\hline & 3 & 1.62 & ND & 2.66 & ND \\
\hline & 4 & 1.62 & ND & 4.86 & ND \\
\hline & 5 & 1.08 & ND & 3.22 & ND \\
\hline & 6 & 1.30 & ND & 2.34 & ND \\
\hline & 7 & 1.67 & ND & 3.32 & ND \\
\hline & 8 & 1.95 & ND & 4.60 & ND \\
\hline & 9 & 3.31 & ND & 4.21 & ND \\
\hline & 10 & 1.54 & ND & 2.49 & ND \\
\hline \multirow{10}{*}{$\begin{array}{l}\text { Dried ginger } \\
\text { ground }\end{array}$} & 1 & 1.47 & ND & 2.18 & 0.15 \\
\hline & 2 & 1.35 & ND & 1.96 & ND \\
\hline & 3 & 1.88 & ND & 2.87 & ND \\
\hline & 4 & 2.06 & ND & 2.87 & ND \\
\hline & 5 & 1.13 & ND & 1.86 & ND \\
\hline & 6 & 1.67 & ND & 2.12 & ND \\
\hline & 7 & 2.45 & 0.23 & 2.57 & ND \\
\hline & 8 & 1.64 & 0.19 & 2.59 & 0.19 \\
\hline & 9 & 1.49 & ND & 2.23 & ND \\
\hline & 10 & 1.58 & 0.15 & 2.11 & ND \\
\hline
\end{tabular}

Note: $\mathrm{ND}=$ Not determined 
Aflatoxins level in all the 10 samples of dried whole ginger was not detected. In dried sliced ginger the range of total aflatoxin was $3.64 \mu \mathrm{g} / \mathrm{kg}-7.52 \mu \mathrm{g} / \mathrm{kg}$, range of aflatoxin $B_{1}$ and $G_{1}$ were $1.08 \mu \mathrm{g} / \mathrm{kg}-3.31 \mu \mathrm{g} / \mathrm{kg}$ and $2.18 \mu \mathrm{g} / \mathrm{kg}-4.86 \mu \mathrm{g} / \mathrm{kg}$ respectively, whereas aflatoxin $B_{2}$ and $G_{2}$ were not detected. In dried ground ginger the range of total aflatoxin was $2.99 \mu \mathrm{g} / \mathrm{kg}-5.25 \mu \mathrm{g} / \mathrm{kg}$, range of aflatoxin $\mathrm{B}_{1}$ and $\mathrm{G}_{1}$ were $1.13 \mu \mathrm{g} / \mathrm{kg}-2.45 \mu \mathrm{g} / \mathrm{kg}$ and $1.86 \mu \mathrm{g} / \mathrm{kg}-2.87 \mu \mathrm{g} / \mathrm{kg}$ respectively, whereas aflatoxin $B_{2}$ and $G_{2}$ were $0.15 \mu \mathrm{g} / \mathrm{kg}-0.23 \mu \mathrm{g} / \mathrm{kg}$ and $0.15 \mu \mathrm{g} / \mathrm{kg}-0.19$ $\mu \mathrm{g} / \mathrm{kg}$. None of the samples were found contaminated above the recommended EU limit set for spices. Multi-mycotoxin analysis on ginger and ginger products in China reported non detection of aflatoxins in ginger powder and ginger peels (Wen et. al. 2014), report from Saudi Arabia revealed that ginger samples were heavily contaminated with Aspergillus flavus and other Aspergillus species suggesting ginger to be more prone towards aflatoxin contamination (Hashem \& Alamri, 2010). This study showed that sliced ginger and ground ginger were more susceptible towards aflatoxins contamination as compared to whole ginger, the susceptibility of the various forms of the dried ginger towards aflatoxins contamination was in the order whole<ground<sliced. The occurrence of aflatoxins $B_{1}$ and $G_{1}$ were more pronounced as compared to aflatoxins $B_{2}$ and $G_{2}$ in the three processed forms of ginger.

\section{CONCLUSION}

The various forms of the ginger studied for the occurrence of aflatoxins suggested that sliced and powdered forms of dried ginger are mostly affected by aflatoxins and it may be due to the favorable sites available for fungal growth and loss of the essential oil during the processing. It is suggested that proper condition for the storage of sliced and ground ginger must be taken in order to avoid aflatoxins contamination. Further survey on the occurrence of mycotoxin in ginger and ginger products must be carried out to establish the occurrence of mycotoxins in various processed forms of ginger.

Acknowledgments: The authors are thankful to Spices Board (Ministry of commerce \& Industry, Government of India) for providing facilities.

\section{REFERENCES}

Ali, B.H., Blunden, G., Tanira, M.O., \& Nemmar, A. (2008). Some phytochemical, pharmacological and toxicological properties of ginger (Zingiber officinale Roscoe): A review of recent research. Food and Chemical Toxicology, 46 (2), 409-420. http://dx.doi.org/10.1016/j.fct.2007.09.085

Bartley, J., \& Jacobs, A. (2000). Effects of drying on flavour compounds in Australian-grown ginger (Zingiber officinale). Journal of the Science of Food and Agriculture, 80, 209-215. http://dx.doi.org/10.1002/(SICI)10970010(20000115)80:2\%3C209::AID-JSFA516\%3E3.0.CO;2-8

Butt, M.S., \& Sultan, M.T. (2011). Ginger and its health claims: Molecular aspects. Critical Reviews in Food Science and Nutrition, 51 (5), 383-393. http://dx.doi.org/10.1080/10408391003624848

Eaton, D.L., \& Gallagher, E.P. (1994). Mechanisms of aflatoxin carcinogenesis. Annual Review of Pharmacology and Toxicology, 34, 135-172. http://dx.doi.org/10.1146/annurev.pa.34.040194.001031

Grzanna, R., Lindmark, L., \& Frondoza, C.G. (2005). Ginger - An herba medicinal product with broad anti-inflammatory actions. Journal of of Medicinal Food, 8 (2), 125-132. http://dx.doi.org/10.1089/jmf.2005.8.125

Hashem, M., \& Alamri, S. (2010). Contamination of common spices in Saudi Arabia markets with potential mycotoxin- producing fungi. Saudi Journal of Biological Sciences, 17, 167-175. http://dx.doi.org/10.1016/j.sjbs.2010.02.011 Iamanaka, B.T., de Menezes, H.C., Vicente, E. Leite, R.S.F., \& Taniwaki, M.H (2007). Aflatoxigenic fungi and aflatoxins occurrence in sultanas and dried figs commercialized in Brazil. Food Control, 18 (5), 454-457. http://dx.doi.org/10.1016/j.foodcont.2005.12.002

Shukla, Y., \& Singh, M. (2007). Cancer preventive properties of ginger: A brief review. Food and Chemical Toxicology, 45, 683-690. http://dx.doi.org/10.1016/j.fct.2006.11.002

Wogan, G.N., Kensler, T.W., \& Groopman, J.D. (2012). Present and future directions of translational research on aflatoxin and hepatocellular carcinoma. A review. Food Additives and Contaminants- Part A, 29 (2), 249-257. http://dx.doi.org/10.1080/19440049.2011.563370

Wen, J., Kong,W., Hu, Y., Wang, J., \& Yang, M. (2014). Multi-mycotoxins analysis in ginger and related products by UHPLC-FLR detection and LCMS/MS confirmation. Food Control, 43, 82-87. http://dx.doi.org/10.1016/j.foodcont.2014.02.038

Whitaker, T.B., Trucksess, M.W.,. Weaver, C.M., \& Slate, A. (2009). Sampling and analytical variability associated with the determination of aflatoxins and ochratoxin A in bulk lots of powdered ginger marketed in 1-lb bags. Analytical and Bioanalytical Chemistry, 395, 1291-1299. http://dx.doi.org/10.1007/s00216009-2880-z 